\title{
HUBUNGAN PENGETAHUAN IBU TENTANG \\ IMUNISASI DASAR DENGAN KELENGKAPAN \\ IMUNISASI DASAR BAYI DI WILAYAH KERJA \\ PUSKESMAS BENDO KABUPATEN MAGETAN
}

\author{
THE CORRELATION BETWEEN MOTHER'S KNOWLEDGE ABOUT BASIC \\ IMMUNIZATION AND COMPLETENESS OF BASIC BABY IMMUNIZATION IN \\ PUSKESMAS BENDO DISTRICT MAGETAN
}

\author{
Dewi Nur Intan Sari, Sri Wahyu Basuki, N.Juni Triastuti, \\ Fakultas Kedokteran Universitas Muhammadiyah Surakarta \\ Korespondensi: dr. Sri Wahyu Basuki Email:Sri.Wahyu@ums.ac.id
}

\begin{abstract}
ABSTRAK
Imunisasi merupakan suatu strategi yang efektif dan efisien dalam meningkatkan derajat kesehatan nasional. Alasan bayi tidak mendapatkan imunisasi lengkap karena faktor informasi, mengakibatkan pengetahuan ibu tentang imunisasi kurang. Tujuan dari penelitian ini adalah untuk mengetahui hubungan pengetahuan ibu dengan kelengkapan imunisasi dasar bayi di wilayah kerja Puskesmas Bendo Kabupaten Magetan. Desain penelitian adalah penelitian observasional analitik dengan pendekatan cross sectional. Sampel penelitian adalah ibu yang datang ke posyandu dengan anaknya berumur 9-12 bulan di wilayah kerja Puskesmas Bendo Kabupaten Magetan dengan teknik pengambilan sampel Cluster sampling.Besar sampel sebanyak 65 responden. Data selanjutnya dianalisis dengan uji Chi-square. Hasil penelitian menunjukkan terdapat hubungan signifikan $(p<0,001)$ antara pengetahuan ibu dengan kelengkapan imunisasi dasar bayi di wilayah kerja Puskesmas Bendo Kabupaten Magetan
\end{abstract}

Kata Kunci: Pengetahuan Ibu, Kelengkapan Imunisasi

\begin{abstract}
Immunization is an effective and efficient strategy to increase national health status. One of the reasons why babies did not get complete immunization is information factor that causes the lack of mother's knowledge about immunization. The aim of this research is to know about the correlation between mother's knowledge about basic immunization and completeness of basic baby immunization in Puskesmas Bendo Magetan district.The design of the research is analytic observational research by employing cross sectional approach. The sample of the research were mothers who came to Posyandu with their 9-12 month babies in working area of Puskesmas Bendo Magetan district. The samples were chosen by using cluster sampling technique. The number of the samples were 65 respondents. The data were analyzed by using chi-square test or alternative Fisher. This research conducted with Chi-square between mother's knowledge variable and the completeness of babies'basic immunization. The result shows the significant score of $p<0,001$. Thus it infers that there is a relasionship between mother's knowledge about basic immunization and completeness of basic baby immunization in working area of Puskesmas Bendo district Magetan..
\end{abstract}

Key words: Mother's knowledge, the completeness of immunization

\section{PENDAHULUAN}

Tingkat kesehatan pada bayi perlu mendapatkan perhatian mengingat bayi atau anak sebagai generasi penerus Bangsa.Salah satu upaya untuk menjadikan generasi yang sehat yaitu dengan mengurangi tingkat morbiditas dan mortalitas pada anak.Selain itu juga dibutuhkan suatu upaya kesehatan yang konsisten (Soetjiningsih, 2012).

Upaya mengurangi tingkat morbiditas dan mortalitas pada anak salah satunya dengan pemberian imunisasi. Imunisasi merupakan salah satu strategi yang efektif dan efisien dalam 
meningkatkan derajat kesehatan nasional dengan mencegah enam penyakit mematikan, yaitu : tuberculosis, dipteri, pertusis, campak, tetanus dan polio. WHO mencanangkan program Expanded Program on Immunization(EPI) dengan tujuan untuk meningkatkan cakupan imunisasi pada anak-anak di seluruh dunia sejak tahun 1974 (Ayubi, 2009).

Menurut DINKES Jawa Timur tahun 2012 menyebutkan bahwa masih tingginya angka kejadian penyakit yang dapat dicegah dengan imunisasi. Angka kejadian luar biasa ini meliputi campak sebesar $1,69 \%$, difteri sebesar $85,65 \%$, hepatitis sebesar 0,19\%, dan pertusis sebesar $0,38 \%$. Sedangkan cakupan imunisasi desa/ kelurahan UCI di Jawa Timur tahun 2012 sebesar $73,02 \%$, angka ini mengalami peningkatan dibandingkan dengan tahun 2011 (DINKES Jatim, 2013). Cakupan desa UCI di Kabupaten Magetan tahun 2013 sebesar 88,51\% dan masih berada di bawah target tahun 2013 yaitu sebesar 95\% (DINKES Kab.Magetan, 2013).

Beberapa alasan bayi tidak mendapatkan imunisasi lengkap yaitu karena alasan informasi, motivasi dan situasi. Alasan informasi berupa kurangnya pengetahuan ibu tentang kebutuhan, kelengkapan dan jadwal imunisasi, ketakutan akan imunisasi dan adanya persepsi salah yang beredar di masyarakat tentang imunisasi. Akan tetapi yang paling berpengaruh adalah karena anak sakit, ketidaktahuan ibu akan pentingnya imunisasi, ketidaktahuan ibu akan pentingnya imunisasi, ketidaktahuan waktu yang tepat untuk mendapatkan imunisasi dan ketakutan akan efek samping yang ditimbulkan imunisasi (MENKES RI, 2010). Dari uraian tersebut menunjukkan bahwa pengetahuan sangat berperan penting terhadap kelengkapan imunisasi pada bayi.

Berdasarkan hasil penelitian yang dilakukan oleh Dewi dkk (2013) di Kelurahan Parupuk Tabing Kota Padang diketahui bahwa persentase pemberian imunisasi dasar lengkap lebih banyak pada ibu yang mempunyai pengetahuan cukup yaitu sebesar $87,5 \%$ dibandingkan dengan ibu yang berpengetahuan kurang yaitu sebesar 4,3\%. Hal ini menunjukkan bahwa peran pengetahuan Ibu tentang imunisasi dasar sangat berpengaruh terhadap kelengkapan imunisasi dasar pada bayi.
Puskesmas Bendo merupakan salah satu tempat pelayanan kesehatan milik pemerintah Kabupaten Magetan yang berada di wilayah Kecamatan Bendo. Di wilayah kerja Puskesmas Bendo tingkat drop out imunisasi dasar dari masing-masing kelurahan masih cukup tinggi yaitu lebih dari 5\%. Drop out imunisasi dasar adalah imunisasi dasar yang tidak lengkap dimana tidak mendapat salah satu atau lebih imunisasi dasar yang meliputi imunisasi Hepatitis B empat kali, BCG satu kali, DPT tiga kali, Polio empat kali, dan Campak satu kali. Cakupan imunisasi lengkap di wilayah kerja Puskesmas Bendo secara global telah memenuhi target akan tetapi masih terdapat beberapa kelurahan yang berada di bawah target yaitu cakupan kurang dari 95\%.

Berdasarkan survey pendahuluan dengan mengamati beberapa posyandu di wilayah kerja Puskesmas Bendo diperoleh kurangnya sarana informasi yang berupa brosur atau poster tentang imunisasi.Hal tersebut dapat mempengaruhi kurangnya pengetahuan Ibu tentang imunisasi. Selain itu, hasil wawancara dari beberapa Ibu di posyandu menyatakan bahwa masih banyak Ibu yang tidak mengetahui manfaat, waktu pemberian, dan jenis dari masing-masing imunisasi yang diberikan kepada bayinya. Oleh karena itu perlu diadakan suatu penelitian tentang kelengkapan imunisasi dasar pada bayi.Berdasarkan uraian di atas penulis tertarik meneliti tentang hubungan pengetahuan ibu tentang imunisasi dasar dengan kelengkapan imunisasi dasar bayi di wilayah kerja Puskesmas Bendo Kabupaten Magetan.

\section{METODE}

Jenis desain penelitian ini adalah penelitian observasional (non-experiment) analitik dengan menggunakan pendekatan cross sectional yang menjelaskan tentang hubungan antara dua variabel, yaitu variabel bebas (pengetahuan ibu tentang imunisasi dasar) dan variabel terikat (kelengkapan imunisasi dasar) (Notoatmodjo, 2010).Penelitian ini dilakukan di wilayah kerja Puskesmas Bendo Kabupaten Magetan.Penelitian ini dilakuakan pada bulan Oktober-November 2015. Populasi pada penelitian ini adalah ibu yang mempunyai anak usia9-12 bulan beserta anaknya yang datang di posyandu tempat dilakukan penelitian di wilayah kerja Puskesmas Bendo Kabupaten Magetan. 
Metode pengambilan sampel yang digunakan adalah Cluster sampling. Sampel dipilih secara acak pada kelompok individu dalam suatu populasi yang terjadi secara alamiah (Dahlan, 2009).Kriteria Inklusi (penerima) terdiri dari Ibu yang mempunyai anak usia 9-12 bulan yang membawa anaknya usia 9-12 bulan baik laki-laki atau perempuan ke posyandu, Ibu membawa KMS yang berisi status imunisasi anak, Bisa membaca dan menulis. Kriteria eksklusi (penolak) terdiri dari Anak usia 9-12 bulan yang datang ke posyandu tidak bersama ibunya, Ibu yang tidak bersedia memberikan data yang nyata dan tidak kooperatif terhadap peneliti. Variabel yang digunakan dalam penelitian ini adalah pengetahuan ibu tentang imunisasi dasar sebagai variabel independent dan kelengkapan imunisasi dasar pada bayi sebagai variabel terikat.Variabel perancu terdiri dari pendidikan, pekerjaan, jarak rumah, jumlah anak. Analisis bivariat dengan menggunakan uji Chisquare.

\section{HASIL DAN PEMBAHASAN}

Tabel 1.Distribusi Karakteristik Ibu yang meliputi umur dan pendidikan

\begin{tabular}{|c|c|c|c|}
\hline \multirow{2}{*}{ Variabel } & \multicolumn{2}{|c|}{ Frekuensi } & \multirow[t]{2}{*}{ Total (\%) } \\
\hline & $\mathbf{N}$ & $\%$ & \\
\hline \multicolumn{4}{|l|}{ Umur } \\
\hline$\leq 20$ tahun & 4 & 6,2 & \\
\hline 21-30 tahun & 31 & 47,6 & $100 \%$ \\
\hline $31-40$ tahun & 30 & 46,2 & \\
\hline \multicolumn{4}{|l|}{ Pendidikan } \\
\hline $\mathrm{SD}$ & 2 & 3,1 & \\
\hline SMP & 13 & 20,0 & \\
\hline SMA/SMK & 41 & 63,1 & $100 \%$ \\
\hline D3 & 1 & 1,5 & \\
\hline S1 & 8 & 12,3 & \\
\hline
\end{tabular}

Sumber: Data primer yang diolah, 2015.

Tabel 2.Distribusi Karakteristik Ibu yang meliputi pekerjaan, jarak rumah, dan jumlah anak

\begin{tabular}{llll}
\hline \multirow{2}{*}{ Variabel } & \multicolumn{2}{c}{ Frekuensi } & Total (\%) \\
\cline { 2 - 4 } & \multicolumn{3}{c}{$\mathbf{N}$} \\
\hline Pekerjaan & 4 & 6,2 & \\
Guru & 30 & 46,2 & \multirow{2}{*}{$100 \%$} \\
Ibu Rumah Tangga & 5 & 7,7 & \\
Petani & 26 & 40,0 & \\
Swasta & &
\end{tabular}

Jarak Rumah

$\begin{array}{llll}100-500 \text { meter } & 44 & 67,7 & \\ 600-1000 \text { meter } & 18 & 27,7 & 100 \% \\ >1000 \text { meter } & 3 & 4,6 & \end{array}$




\begin{tabular}{cccc}
\hline \multirow{2}{*}{ Variabel } & \multicolumn{2}{c}{ Frekuensi } & Total (\%) \\
\cline { 2 - 4 } & $\mathbf{N}$ & $\mathbf{\%}$ & \\
\hline Jumlah Anak & & & \\
1 & 21 & 32,2 & \\
2 & 29 & 44,6 & \multirow{2}{*}{$100 \%$} \\
3 & 13 & 20,0 & \\
4 & 2 & 3,1 & \\
\hline
\end{tabular}

Tabel 3.Distribusi Karakteristik Bayi yang meliputi Usia dan jenis kelamin

\begin{tabular}{llccc}
\hline \multirow{2}{*}{ Variabel } & \multicolumn{2}{c}{ Frekuensi } & \multirow{2}{*}{ Total (\%) } \\
\cline { 3 - 4 } & & $\mathbf{N}$ & $\mathbf{\%}$ & \\
\hline Usia & & 15 & 23,1 & \\
& 9 bulan & 18 & 27,7 & \multirow{2}{*}{$100 \%$} \\
& 10 bulan & 8 & 12,3 & \\
11 bulan & 24 & 36,9 & \\
12 bulan & & & \\
& & & \multirow{2}{*}{$100 \%$} \\
Jenis Kelamin & 32 & 49,2 & \\
$\quad$ Laki-laki & 33 & 50,8 &
\end{tabular}

Sumber: Data primer yang diolah, 2015

Tabel 4.Status Imunisasi Dasar Bayi

\begin{tabular}{lcc}
\hline \multicolumn{1}{c}{ Status Imunisasi } & Frekuensi & Persentase \\
\hline Lengkap & 43 & 66,2 \\
Tidak Lengkap & 22 & 33,8 \\
Total & 65 & 100,0 \\
\hline
\end{tabular}

Sumber: Data primer yang diolah, 2015

Tabel 5.Pengetahuan Ibu tentang Imunisasi Dasar

\begin{tabular}{lcc}
\hline \multicolumn{1}{c}{ Pengetahuan Ibu } & Frekuensi & Persentase \\
\hline Baik & 34 & 52,3 \\
Kurang Baik & 31 & 47,7 \\
Total & 65 & 100,0 \\
\hline
\end{tabular}

Sumber: Data primer yang diolah, 2015

Tabel 6. Hubungan Pengetahuan Ibu tentang Imunisasi Dasar dengan Kelengkapan Imunisasi Dasar pada Bayi

\begin{tabular}{lcccccc}
\hline & \multicolumn{9}{c}{ Status Imunisasi } & \multirow{2}{*}{ Pengetahuan Ibu } & \multicolumn{2}{c}{ Lengkap } & Tidak Lengkap & P & Prevalensi Ratio \\
& N & \% & N & \% & & \\
\hline Baik & 32 & 49,2 & 2 & 3,1 & & \\
Kurang Baik & 11 & 16,9 & 20 & 30,8 & $<0,001$ & 2,652 \\
Total & 43 & 66,2 & 22 & 33,8 & & \\
\hline
\end{tabular}

Sumber: Data primer yang diolah, 2015 
Berdasarkan hasil analisis karakteristik ibu yang telah dijelaskan di atas bahwa sebagian besar ibu berumur 21-30 tahun, pada usia tersebut tergolong usia yang produktif yaitu ibu dengan mudah dapat menerima informasi dan dapat memahaminya. Status pendidikan ibu mayoritas berpendidikan setara dengan SMA hal ini menunjukkan pola pikir ibu tentang imunisasi seharusnya baik, dimana ibu mempunyai kesadaran untuk mengimunisasikan bayinya.Hasil penelitian juga menunjukkan sebagian besar responden adalah ibu rumah tangga, dengan pekerjaan menjadi ibu rumah tangga, ibu mempunyai waktu dan perhatian yang cukup untuk status imunisasi bayinya sehingga memungkinkan bayi untuk mendapat imunisasi secara tepat waktu dan lengkap.Jarak rumah responden dengan posyandu sebagian besar 100-500 meter, sehingga akses terhadap sarana pemberian imunisasi tergolong sangat memungkinkan. Sedangkan untuk jumlah anak mayoritas mempunyai dua anak dimana dengan jumlah anak yang sedikit maka Ibu akan lebih patuh untuk mengimunisasikan anaknya. Karakteristik bayi yang diteliti menunjukkan sebanyak $50,8 \%$ berjenis kelamin perempuan, sedangkan usia bayi yang diteliti yaitu bayi dengan usia 9-12 bulan. Hasil analisis menunjukkan mayoritas bayi berusia 12 bulan, pada usia tersebut seharusnya semua bayi yang menjadi responden mempunyai status imunisasi dasar yang lengkap.

Berdasarkan hasil analisis yang telah dikemukakan di atas dapat diketahui bahwa sebagian besar ibu yang mempunyai bayi di wilayah kerja Puskesmas Bendo mempunyai pengetahuan yang baik tentang imunisasi dasar dan lainnya mempunyai pengetahuan yang kurang baik. Hasil penelitian yang dilihat berdasarkan kuesioner yang telah diberikan kepada ibu di wilayah kerja Puskesmas Bendo menunjukkan sebagian besar ibu menjawab salah atau tidak mengetahui frekuensi pemberian imunisasi Hepatitis B yang diberikan pada bayi, frekuensi pemberian imunisasi polio pada bayi, cara pemberian imunisasi polio, frekuensi pemberian imunisasi DPT pada bayi dan frekuensi pemberian imunisasi campak pada bayi, imunisasi yang diberikan pertama kali saat bayi baru lahir dan sebagian besar ibu mengetahui atau dapat menjawab dengan benar tentang penyakit yang dapat dicegah dengan imunisasi, tempat pemberian imunisasi, cara pemberian imunisasi campak dan pengertian imunisasi. Hasil penelitian juga didapatkan masih banyak ibu yang tidak dapat membedakan pemberian imunisasi jenis apa saja yang diberikan melalui suntikan dan melalui oral. Terdapat $52,3 \%$ ibu yang mempunyai tingkat pengetahuan yang baik, hal ini dipengaruhi oleh tingkat pendidikan dan usia ibu yang tergolong produktif dan ibu mendapatkan informasi tentang imunisasi dari berbagai sumber.

Berdasarkan hasil penelitian yang telah dikemukakan di atas diketahui bahwa sebagian besar bayi di wilayah kerja Puskesmas Bendo mempunyai status imunisasi lengkap yaitu sebanyak $66,2 \%$ bayi sedangkan yang mempunyai status imunisasi tidak lengkap sebanyak 33,8\% bayi. Hal-hal yang mempengaruhi pemberian imunisasi yang lengkap yaitu ibu mempunyai pengetahuan yang baik tentang imunisasi, ibu mempunyai tingkat kesadaran yang tinggi akan pencegahan penyakit untuk anaknya serta ibu merasa pemberian imunisasi sangat penting untuk anaknya. Selain itu masih terdapat pula bayi yang mempunyai status imunisasi tidak lengkap yaitu biasanya ketidaklengkapan imunisasi pada pemberian imunisasi DPT-HB-1, Polio 2 , DPTHB-3, Polio 4 serta campak dikarenakan beberapa faktor antara lain ibu mempunyai pengetahuan yang kurang tentang jadwal pemberian imunisasi sehingga waktu pemberian imunisasi terlambat.

Berdasarkan hasil penelitian menunjukkan bahwa sebanyak $49,2 \%$ bayi mempunyai status imunisasi yang lengkap dengan pengetahuan ibu yang baik sedangkan sebanyak $30,8 \%$ bayi mempunyai status imunisasi tidak lengkap dengan pengetahuan ibu yang kurang baik, hal ini menunjukkan sebagian besar ibu yang mempunyai pengetahuan yang baik akan memberikan imunisasi dasar yang lengkap kepada bayinya. Hasil uji statistik dengan menggunakan analisis Chi-square diketahui bahwa nilaip $<0,001$, hal ini mempunyai arti bahwa terdapat hubungan yang signifikan antara pengetahuan ibu tentang imunisasi dasar dengan kelengkapan imunisasi dasar bayi di wilayah kerja Puskesmas Bendo Kabupaten Magetan, artinya semakin baik tingkat pengetahuan ibu tentang imunisasi dasar maka ibu akan memberikan imunisasi secara lengkap kepada bayinya. Berdasarkan perhitungan statistik juga didapatkan nilai Prevalensi Rasio sebesar 2,652 dengan interval kepercayaan 95\%.Sehingga 
dapat disimpulkan bahwa bayi dengan ibu yang berpengetahuan baik mempunyai peluang memperoleh imunisasi dasar lengkap sebesar 2,652 kali dibandingkan dengan bayi dengan ibu yang berpengetahuan kurang baik.

Hal tersebut menunjukkan bahwa pengetahuan ibu mempengaruhi status imunisasi pada bayinya, dimana bayi yang mempunyai ibu dengan pengetahuan tentang imunisasi yang baik akan mempunyai status imunisasi dasar yang lengkap dibandingkan dengan bayi dengan ibu yang berpengetahuan kurang baik terhadap imunisasi. Hasil penelitian ini sesuai dengan penelitian yang dilakukan Bofarraj (2011) yang meneliti tentang pengetahuan, sikap dan praktek ibu dalam pemberian imunisasi pada bayi dan anak pra-sekolah, hasilnya jenis kelamin anak, pendidikan ibu, tempat tinggal dan pekerjaan ibu tidak berpengaruh terhadap status imunisasi bayi akan tetapi sikap yang negatif berupa pengetahuan yang kurang dan praktik yang tidak sesuai berpengaruh terhadap kelengkapan imunisasi.

Berdasarkan hasil penelitian didapatkan masih terdapat beberapa ibu yang mempunyai pengetahuan yang baik tetapi status imunisasi bayinya tidak lengkap $(3,1 \%)$ kemungkinan ada beberapa faktor yang mempengaruhi yaitu ibu meragukan keamanan dari vaksin dan banyak ibu yang tidak mengetahui frekuensi pemberian masing-masing imunisasi. Hal ini sejalan dengan penelitian yang dilakukan oleh Abdulraheem et al (2011) tentang alasan ketidaklengkapan vaksinasi, hasilnya menunjukkan bahwa alasan ibu tidak memberikan imunisasi secara lengkap antara lain Ibu meragukan keamanan imunisasi, jarak rumah yang jauh, antrian yang lama di fasilitas kesehatan, dan kurangnya pemahaman tentang kontraindikasi pemberian imunisasi.

Pengetahuan tentang imunisasi mencakup tahu akan pengertian imunisasi, penyakit yang dapat dicegah melalui imunisasi, manfaat imunisasi, tempat pelayanan imunisasi, waktu pemberian imunisasi, jenis imunisasi dan jumlah pemberian imunisasi. Melalui pengetahuan yang cukup diharapkan dapat mempengaruhi tindakan seorang ibu dalam memberikan imunisasi secara lengkap kepada anaknya (Budiman dan Agus, 2014). Hasil penelitian ini juga sejalan dengan teori dalam Notoatmodjo (2007), menyatakan bahwa terdapat kecenderungan seseorang yang berpengetahuan tinggi akan cenderung mempunyai perilaku yang baik dalam bidang kesehatan dalam hal ini untuk mengimunisasikan anaknya.

Keterbatasan dari penelitian ini antara lain penelitian ini hanya dikhususkan di wilayah kerja Puskesmas Bendo Kabupaten Magetan sehingga tidak dapat digeneralisasikan di wilayah lain, dalam penelitian ini masing-masing daerah mempunyai perlakuan yang berbeda dimana terdapat daerah yang sudah mendapat penyuluhan sedang daerah yang lain belum pernah mendapat penyuluhan tentang imunisasi, selain itu peneliti tidak dapat mengendalikan beberapa variabel perancu yang memungkinkan dapat mempengaruhi hasil dari penelitian.

\section{SIMPULAN}

Berdasarkan penelitian dan hasil dari analisis data, maka diperoleh kesimpulan bahwa terdapat hubungan yang signifikan antara pengetahuan ibu tentang imunisasi dasar dengan kelengkapan imunisasi dasar pada bayi di wilayah kerja Puskesmas Bendo Kabupaten Magetan.

\section{PERSANTUNAN}

Ucapan terima kasih kepada ibu yang berada di posyandu di wilayah kerja Puskesmas Bendo Kabupaten Magetan yang bersikap kooperatif dalam lancarnya penelitian ini dan bersedia menjadi responden dalam penelitian. Terima kasih kepada pihak Puskesmas Bendo Kabupaten Magetan yang telah menyediakan sarana dan prasarana serta memeberikan ijin diadakan penelitian ini sehingga penelitian dapat berjalan dengan lancar.

\section{DAFTAR PUSTAKA}

Abdulraheem, I.S., Onajole.A.T., Jimoh.A.A.G., Oladipo.A.R., 2011. Reason for incomplete vaccination and factors for missed opportunities among rural Nigerian children.Journal of Public Health and Epidemiology Vol.3(4).

Ayubi, D., 2009. Kontribusi Pengetahuan Ibu terhadap Status Imunisasi Anak di Tujuh Provinsi di Indonesia.Jurnal Pembangunan Manusia, vol.7 No.1. 
Bofarraj, M., 2011.Knowledge, attitude and practices of mothers regarding immunization of infants and preschool children at AlBeida City, Libya 2008.Egypt J Pediatr Allergy Immunol 9(1).

Budiman dan Agus, R., 2014.Kapita Selekta Kuesioner Pengetahuan dan Sikap dalam Penelitian Kesehatan. Jakarta: Salemba Medika.

Dewi ,A.P., Eryati D., Edison., 2013. Hubungan Tingkat Pengetahuan Ibu dengan Pemberian Imunisasi Dasar Lengkap pada Bayi di Kelurahan Parupuk Tabing Wilayah Kerja Puskesmas Lubuk Buaya Kota Padang Tahun 2013.Jurnal Kesehatan Andalas, 3(2):114-118.

Dinas Kesehatan Kabupaten Magetan., 2013. Profil Kesehatan Kabupaten Magetan. Magetan: Dinas Kesehatan Kabupaten Magetan.
Dinas Kesehatan Provinsi Jawa Timur., 2013. Profil Kesehatan Provinsi Jawa Timur Tahun 2012. Surabaya: Dinas Kesehatan Provinsi Jawa Timur.

Mentri Kesehatan RI. 2010., Keputusan Mentri Kesehatan RI No.482. Jakarta: Kementrian Kesehatan RI.

Notoatmodjo, S., 2007.Promosi Kesehatan dan Ilmu Perilaku. Jakarta: Rineka Cipta.

Notoatmodjo, S., 2010. Ilmu Perilaku Kesehatan. Jakarta: Rineka Cipta.

Notoatmodjo, S., 2010. Metodologi Penelitian Kesehatan. Jakarta: Rineka Cipta.

Soetjiningsih., 2012. Tumbuh Kembang Anak. Jakarta: Penerbit Buku Kedokteran EGC. 